Pacific Journal of Mathematics

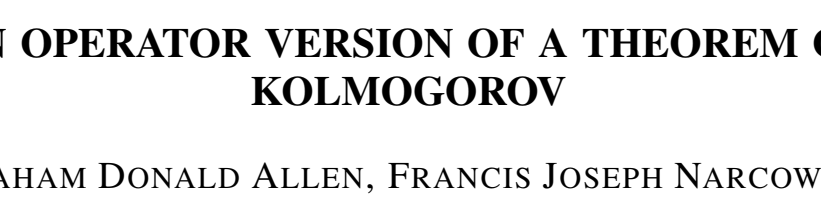




\title{
AN OPERATOR VERSION OF A THEOREM OF KOLMOGOROV ${ }^{1}$
}

\author{
G. D. Allen, F. J. Narcowich and J. P. Williams
}

Let $\mathscr{G}$ be a (separable) Hausdorff space and let $K$ be a continuous nonnegative-definite kernel (covariance) from $\mathscr{G} \times$ $\mathscr{G}$ to $C$. The well known theorem of Kolmogoror states that in the case $\mathscr{G}$ is the set of integers there is a continuous mapping (stochastic process) $x(\cdot)$ from $\mathscr{G}$ into a (separable) Hilbert space $\mathscr{K}$ such that $K(s, t)=(x(s), x(t))$. The theorem is also known for any separable Hausdorff space. The purpose of this paper is to replace the complex numbers $C$ by the algebra $B(\mathscr{H}, \mathscr{C})$ of bounded linear operators from a Hilbert space into itself. The factorization is then $K(t, s)=X(t) * X(s)$ with $X$ a continuous map from $\mathscr{G}$ to $B(\mathscr{H}, \mathscr{K})$ for a suitable Hilbert space $\mathscr{K}$. If $\mathscr{G}$ is separable we may take $\mathscr{K}=\mathscr{H}$.

Two proofs of this theorem are given. The first, for $\mathscr{G}$ separable and $\mathscr{H}$ of arbitrary dimension, uses an extension of the technique of [1] to obtain a triangular factorization for nonnegative-definite matrices with operator entries to construct the desired stochastic process $X(\cdot)$. The second, for $\mathscr{G}$ arbitrary and $\mathscr{H}$ of infinite dimension uses the techniques of reproducing kernel Hilbert spaces, and is a bit simpler.

Main results. Let $\mathscr{H}$ be a complex Hilbert space and let $B(\mathscr{H}, \mathscr{H})$ be the bounded linear operators on. Let $\mathscr{G}$ be a Hausdorff space and let $K: \mathscr{G} \times \mathscr{G} \rightarrow B(\mathscr{H}, \mathscr{H})$ be a (jointly) continuous function. We say that $K$ is nonnegative-definite if for every $t_{1}, \cdots$, $t_{n} \in \mathscr{G}$ and $x_{1}, \cdots, x_{n} \in \mathscr{H}$ the sum

$$
\sum_{i, j=1}^{n}\left(K\left(t_{i}, t_{j}\right) x_{j}, x_{i}\right) \geqq 0 .
$$

The generalization of the Kolmogorov theorem we wish to prove is contained in

THEOREM 1. Let $\mathscr{G}$ be a separable Hausdorff space. If $K(\cdot, \cdot)$ is a continuous nonnegative-definite function from $\mathscr{G} \times \mathscr{G}$ into $B(\mathscr{H}, \mathscr{H})$ then there exists a separable Hilbert space $\mathscr{K}$ and a continuous function $X(t)$ from $\mathscr{G}$ into $B(\mathscr{H}, \mathscr{K})$ such that

$$
X^{*}(t) X(s)=K(t, s) .
$$

1 This generalization was suggested to the authors by Professor P. Masani in January 1975. 
In order to prove this theorem we require a number of facts about operator-valued matrices and about the solution of operator equations. The first result, is due to Douglas [2]. (See also FillmoreWilliams [4].) We will denote the range of the operator $A$ by $\mathscr{R}(A)$, and the kernel of $A$ by $\mathscr{N}(A)$.

Lemma 1. Let $A$ and $B$ be bounded operators on $\mathscr{H}$. Then the following conditions are equivalent:

(i) $\mathscr{R}(A) \subset \mathscr{R}(B)$,

(ii) $A=B C$, for some bounded operator $C$ on $\mathscr{H}$,

(iii) $A A^{*} \leqq \lambda^{2} B B^{*}$, for some $\lambda>0$.

Moreover, the operator $C$ can be chosen so that $\mathscr{N}\left(C^{*}\right) \supset \mathscr{N}(B)$ and $\mathscr{R}(C) \subset \overline{\mathscr{R}}(\bar{B})$.

COROLLARY. If $B$ is bounded and nonnegative then $\mathscr{R}(\sqrt{B}) \supset$ $\mathscr{R}(B)$.

If we restrict $K$, of Theorem 1 , to a finite subset of $\mathscr{G}$ the kernel $K$ becomes a $n \times n$ matrix whose $(i, j)$ entry is $K_{i j}=K\left(t_{i}, t_{j}\right)$, $1 \leqq i, j \leqq n$. This matrix is nonnegative-definite in the sense that for every $x_{1}, x_{2}, \cdots, x_{n} \in \mathscr{H}$,

$$
\sum_{i, j=1}^{n}\left(K_{i j} x_{j}, x_{i}\right) \geqq 0 \text {. }
$$

Denote by $\mathscr{H}_{n}$ the space which is a direct sum of $n$ copies of $\mathscr{H}$, $\mathscr{H}_{n}=\mathscr{H} \oplus \cdots \oplus \mathscr{H}$, with the natural inner product. Suppose that $K$ is an operator on $\mathscr{H}_{n}$; that is, $K$ is an $n \times n$ operatorvalued matrix. Then (2) means that $(K x, x) \geqq 0$ for every $x=$ $\left(x_{1}, \cdots, x_{n}\right) \in \mathscr{H}_{n}$, that is $K$ is a nonnegative operator on $\mathscr{H}_{n}$. Note that if $K$ is nonnegative-definite, $K_{i j}=K_{j i}^{*}$, for all $1 \leqq i, j \leqq n$. If $K$ is an $n \times n$ operator-valued matrix and $m \leqq n$, we write $K_{m}$ for the upper left $m \times m$ submatrix of $K$.

LEMma 2. Let $K$ be an $n \times n$ nonnegative definite, bounded operator-valued mat1 Then there is a positive constant $\lambda$ so that

$$
K_{i i} \geqq \lambda K_{i j} K_{i j}^{*}, 1 \leqq i<j \leqq n .
$$

Proof. Let $V_{i}: \mathscr{H} \rightarrow \mathscr{H}_{n}$ where $V_{i} h=(0, \cdots, h, 0 \cdots 0), h$ being in the $i$ th position. If $h \in \mathscr{H}$, then

$$
\begin{aligned}
\left|K_{i j}^{*} h\right|^{2} & =\left|K_{j i} h\right|^{2}=\left|V_{j}^{*} K V_{i} h\right|^{2} \leqq\left|K V_{i} h\right|^{2} \\
& =\left(V_{i}^{*} K^{2} V_{i} h, h\right) \leqq|K|\left(V_{i}^{*} K V_{i} h, h\right)=|K|\left(K_{i i} h, h\right) .
\end{aligned}
$$

Thus $K_{i j} K_{i j}^{*} \leqq|K| K_{i i}$. 
We must show that

$$
T_{n-1, n-1} T_{n-1, n}=K_{n-1, n}-\sum_{i=1}^{n-2} T_{i, n-1}^{*} T_{i, n}
$$

has a bounded solution for $T_{n-1, n}$. By the Remark we have for any $z_{n-1} \in \mathscr{H}$ a vector $z_{n-2} \in \mathscr{H}$ such that

$$
T_{n-2, n-2} z_{n-2}+T_{n-2, n-1} z_{n-1}=0 \text {. }
$$

Thus, proceeding sequentially we can solve the equations

$$
\sum_{j=i}^{n-1} T_{i j} z_{j}=0, \quad i=n-2, n-3, \cdots, 1
$$

for $z_{n-2}, z_{n-3}, z_{n-4}, \cdots, z_{1}$, given $z_{n-1}$. Now, if $z=\left(z_{1}, \cdots, z_{n}\right)$, an application of (11) gives

$$
\begin{aligned}
(K z, z)= & \sum_{j=1}^{n-2}\left(K_{n j} z_{j}, z_{n}\right)+\sum_{j=1}^{n-2}\left(K_{j n} z_{n}, z_{j}\right)+\left(K_{n-1, n} z_{n}, z_{n-1}\right) \\
& +\left(K_{n, n-1} z_{n-1}, z_{n}\right)+\left(K_{n n} z_{n}, z_{n}\right)+\left(T_{n-1, n-1}^{2} z_{n-1}, z_{n-1}\right) .
\end{aligned}
$$

By (9),

$$
\begin{aligned}
\sum_{j=1}^{n-2}\left(K_{j n} z_{n}, z_{j}\right) & =\sum_{j=1}^{n-2}\left(\left(T_{j j} T_{j n}+\sum_{i=1}^{j-1} T_{i j}^{*} T_{i n}\right) z_{n}, z_{j}\right) \\
& =\sum_{j=1}^{n-2}\left(T_{j n} z_{n}, T_{j j} z_{j}\right)+\sum_{j=1}^{n-2} \sum_{i=1}^{j-1}\left(T_{i j}^{*} T_{i n} z_{n}, z_{j}\right) .
\end{aligned}
$$

We interpret all sums over not well defined limits to be zero (e.g. $\left.\sum_{i=1}^{0}(\cdot)=0\right)$. From (11) we have

$$
T_{j j} z_{j}=-\sum_{i=j+1}^{n-1} T_{j i} z_{i} .
$$

Substitution into (13) gives

$$
\begin{aligned}
\sum_{j=1}^{n-2}\left(K_{j n} z_{n}, z_{j}\right)= & -\sum_{j=1}^{n-2} \sum_{i=j+1}^{n-1}\left(T_{j n} z_{n}, T_{j i} z_{i}\right)+\sum_{j=1}^{n-2} \sum_{i=1}^{j-1}\left(T_{i n} z_{n}, T_{i j} z_{j}\right) \\
= & -\sum_{j=1}^{n-3} \sum_{i=j+1}^{n-2}\left(T_{j n} z_{n}, T_{j i} z_{i}\right)+\sum_{j=1}^{n-2} \sum_{i=1}^{j-1}\left(T_{i n} z_{n}, T_{i j} z_{j}\right) \\
& -\sum_{j=1}^{n-2}\left(T_{j n} z_{n}, T_{j, n-1} z_{n-1}\right) .
\end{aligned}
$$

The last term of (14) is

$$
-\sum_{j=1}^{n-2}\left(T_{j, n-1}^{*} T_{j n} z_{n}, z_{n-1}\right) .
$$

Interchanging limits in the second term on the right hand side of (14), the equation (14) becomes 
we will employ Lemma 1 (iii). ( $T_{13}$ is obtained in the same way as $T_{12}$.) According to the Remark above we take $T_{11} z_{1}=-T_{12} z_{2}$, for some $z_{2} \in \mathscr{H}$. If $z=\left(z_{1}, z_{2}, z_{3}\right)$, then

$$
\begin{aligned}
0 \leqq & \left(K_{3} z, z\right)=\left(T_{11}^{2} z_{1}, z_{1}\right)+\left(T_{11} T_{12} z_{2}, z_{1}\right)+\left(T_{12}^{*} T_{11} z_{1}, z_{2}\right) \\
& +\left(\left(T_{22}^{2}+T_{12}^{*} T_{12}\right) z_{2}, z_{2}\right)+\left(T_{11} T_{13} z_{3}, z_{1}\right) \\
& +\left(K_{23} z_{3}, z_{2}\right)+\left(K_{32} z_{2}, z_{3}\right)+\left(K_{33}, z_{3}, z_{3}\right)
\end{aligned}
$$

which, since $T_{11} z_{1}=-T_{12} z_{2}$ equals

$$
\left(T_{22}^{2} z_{2}, z_{2}\right)+\left(\left(K_{23}-T_{12}^{*} T_{13}\right) z_{3}, z_{2}\right)+\left(\left(K_{32}-T_{13}^{*} T_{12}\right) z_{2}, z_{3}\right)+\left(K_{33} z_{3}, z_{3}\right) .
$$

In matrix form this means, for every $z_{2}, z_{3} \in \mathscr{H}$,

$$
\left(\left(\begin{array}{cc}
T_{22}^{2} & K_{23}-T_{12}^{*} T_{13} \\
\left(K_{23}-T_{12}^{*} T_{13}\right)^{*} & K_{33}
\end{array}\right)\left(\begin{array}{c}
z_{2} \\
z_{3}
\end{array}\right), \quad\left(\begin{array}{c}
z_{2} \\
z_{3}
\end{array}\right)\right) \geqq 0 .
$$

By Lemma 2, then, there is a positive $\lambda$ such that

$$
T_{22}^{2} \geqq \lambda\left(K_{23}-T_{12}^{*} T_{13}\right)\left(K_{23}-T_{12}^{*} T_{13}\right)^{*},
$$

and hence by the Corollary and Lemma 2 (ii) $T_{23}$ exists and is a bounded operator. Moreover, by Lemma $1 \mathscr{R}\left(T_{23}\right) \subset \overline{\mathscr{R}}\left(T_{22}\right)$. (This last fact together with the Remark is interpreted to mean that for any $y \in \mathscr{H}$ there is an $x \in \mathscr{H}$ so that $T_{22} x+T_{23} y=0$.)

To show that $T_{33}$ exists is now routine. Let $z=\left(z_{1}, z_{2}, z_{3}\right)$. Then

$$
\begin{gathered}
\left(\left(K_{33}-T_{13}^{*} T_{13}-T_{23}^{*} T_{23}\right) z_{3}, z_{3}\right)=(K z, z)-\left|T_{22} z_{2}+T_{23} z_{3}\right|^{2} \\
\quad-\left|T_{11} z_{1}+T_{12} z_{2}+T_{13} z_{3}\right|^{2} \\
\geqq-\left|T_{22} z_{2}+T_{23} z_{3}\right|^{2}-\left|T_{11} z_{1}+T_{12} z_{2}+T_{13} z_{3}\right|^{2} .
\end{gathered}
$$

This inequality, combined with the Remark above gives the nonnegativity of $K_{3}-T_{13}^{*} T_{13}-T_{23}^{*} T_{23}$ and hence the existence of and boundedness of $T_{33}$.

We pass to the induction. Assume that $T_{k}^{*} T_{k}=K_{k}, k=1,2, \cdots$, $n-1$. Solve for $T_{1 n}$ in the same way as for $T_{12}$. Proceeding, once again, by induction we assume that the $T_{k n}$ exist and are bounded for $k=2,3, \cdots, n-2$, and also that $\mathscr{R}\left(T_{k n}\right) \subset \overline{\mathscr{R}}\left(T_{k k}\right)$, which makes the Remark applicable. The formula for the $T_{k m}$ are given by

$$
T_{k k} T_{k m}=K_{k m}-\sum_{i=1}^{k-1} T_{i k}^{*} T_{i m}, k \leqq m,
$$

or

$$
K_{k m}=\sum_{i=1}^{k} T_{i k}^{*} T_{i m}
$$


We must show that

$$
T_{n-1, n-1} T_{n-1, n}=K_{n-1, n}-\sum_{i=1}^{n-2} T_{2, n-1}^{*} T_{i, n}
$$

has a bounded solution for $T_{n-1, n}$. By the Remark we have for any $z_{n-1} \in \mathscr{H}$ a vector $z_{n-2} \in \mathscr{H}$ such that

$$
T_{n-2, n-2} z_{n-2}+T_{n-2, n-1} z_{n-1}=0 \text {. }
$$

Thus, proceeding sequentially we can solve the equations

$$
\sum_{j=i}^{n-1} T_{i j} z_{j}=0, \quad i=n-2, n-3, \cdots, 1
$$

for $z_{n-2}, z_{n-3}, z_{n-4}, \cdots, z_{1}$, given $z_{n-1}$. Now, if $z=\left(z_{1}, \cdots, z_{n}\right)$, an application of (11) gives

$$
\begin{aligned}
(K z, z)= & \sum_{j=1}^{n-2}\left(K_{n j} z_{j}, z_{n}\right)+\sum_{j=1}^{n-2}\left(K_{j n} z_{n}, z_{j}\right)+\left(K_{n-1, n} z_{n}, z_{n-1}\right) \\
& +\left(K_{n, n-1} z_{n-1}, z_{n}\right)+\left(K_{n n} z_{n}, z_{n}\right)+\left(T_{n-1, n-1}^{2} z_{n-1}, z_{n-1}\right) .
\end{aligned}
$$

By (9),

$$
\begin{aligned}
\sum_{j=1}^{n-2}\left(K_{j n} z_{n}, z_{j}\right) & =\sum_{j=1}^{n-2}\left(\left(T_{j j} T_{j n}+\sum_{i=1}^{j-1} T_{i j}^{*} T_{i n}\right) z_{n}, z_{j}\right) \\
& =\sum_{j=1}^{n-2}\left(T_{j n} z_{n}, T_{j j} z_{j}\right)+\sum_{j=1}^{n-2} \sum_{i=1}^{j-1}\left(T_{i j}^{*} T_{i n} z_{n}, z_{j}\right) .
\end{aligned}
$$

We interpret all sums over not well defined limits to be zero (e.g. $\sum_{i=1}^{0}(\cdot)=0$ ). From (11) we have

$$
T_{j j} z_{j}=-\sum_{i=j+1}^{n-1} T_{j i} z_{i} .
$$

Substitution into (13) gives

$$
\begin{aligned}
\sum_{j=1}^{n-2}\left(K_{j n} z_{n}, z_{j}\right)= & -\sum_{j=1}^{n-2} \sum_{i=j+1}^{n-1}\left(T_{j n} z_{n}, T_{j i} z_{i}\right)+\sum_{j=1}^{n-2} \sum_{i=1}^{j-1}\left(T_{i n} z_{n}, T_{i j} z_{j}\right) \\
= & -\sum_{j=1}^{n-3} \sum_{i=j+1}^{n-2}\left(T_{j n} z_{n}, T_{j i} z_{i}\right)+\sum_{j=1}^{n-2} \sum_{i=1}^{j-1}\left(T_{i n} z_{n}, T_{i j} z_{j}\right) \\
& -\sum_{j=1}^{n-2}\left(T_{j n} z_{n}, T_{j, n-1} z_{n-1}\right) .
\end{aligned}
$$

The last term of (14) is

$$
-\sum_{j=1}^{n-2}\left(T_{j, n-1}^{*} T_{j n} z_{n}, z_{n-1}\right) .
$$

Interchanging limits in the second term on the right hand side of (14), the equation (14) becomes 


$$
\begin{aligned}
& -\sum_{j=1}^{n-3} \sum_{i=j+1}^{n-2}\left(T_{j n} z_{n}, T_{j i} z_{i}\right)+\sum_{i=1}^{n-3} \sum_{j=i+1}^{n-2}\left(T_{i n} z_{n}, T_{i j} z_{j}\right) \\
& -\sum_{j=1}^{n-2}\left(T_{j, n-1}^{*} T_{j n} z_{n}, z_{n-1}\right) .
\end{aligned}
$$

Upon interchanging $i$ and $j$ we obtain

$$
\sum_{j=1}^{n-2}\left(K_{j n} z_{n}, z_{j}\right)=-\sum_{j=1}^{n-2}\left(T_{j, n-1}^{*} T_{j n} z_{n}, z_{n-1}\right)
$$

Similarly

$$
\sum_{j=1}^{n-2}\left(K_{n j} z_{j}, z_{n}\right)=-\left(\sum_{j=1}^{n-2} T_{j n}^{*} T_{j, n-1} z_{n-1}, z_{n}\right)
$$

Substituting (15) and (16) into (12) and writing the result in matrix form we have

$$
\begin{aligned}
0 \leqq & \left(K_{n} x, x\right) \\
& =\left(\left(\begin{array}{cc}
T_{n-1, n-1}^{2} & K_{n-1, n}-\sum_{j=1}^{n-2} T_{j, n-1}^{*} T_{j n} \\
\left(K_{n-1, n}-\sum_{j=1}^{n-2} T_{j, n-1}^{*} T_{j n}\right)^{*} & K_{n n}
\end{array}\right)\left(\begin{array}{l}
z_{n-1} \\
z_{n}
\end{array}\right), \quad\left(\begin{array}{l}
z_{n-1} \\
z_{n}
\end{array}\right)\right)
\end{aligned}
$$

An application of Lemmas 1 and 2 and the Corollary (ii), (iii) gives that there is a bounded operator $T_{n-1, n}$ satisfying (10) and moreover that $\mathscr{R}\left(T_{n-1, n}\right) \subseteq \overline{\mathscr{R}}\left(T_{n-1, n-1}\right)$.

To show that $T_{n n}$ exists a similar argument is used. This completes the induction and the Lemma is proved.

Lemma 3 works in any Hilbert space $\mathscr{H}$, finite or infinite dimensional. The following result, a considerable improvement of Lemma 3 , applies only to infinite dimensional Hilbert spaces.

Lemma 3'. (a) Suppose $\operatorname{dim} \mathscr{H}=\infty$ of $K$ is a nonegative $n \times n$ matrix with entries $K_{i j} \in B(\mathscr{H}, \mathscr{H})$ then there exist $X_{1}, X_{2}, \cdots, X_{n}$ in $B(\mathscr{H}, \mathscr{H})$ such that $K_{i j}=X_{i}^{*} X_{j}(1 \leqq i, j \leqq n)$. Hence $K=X^{*} X$ where $X$ is the $n \times n$ matrix whose first row is $\left(X_{1} X_{2} \cdots X_{n}\right)$ and whose other entries are all 0.

(b) If $A$ is an $n \times n$ matrix with entries $A_{i j} \in B(\mathscr{H}, \mathscr{H})$ then there exists a partial isometry $U=\left(U_{i j}\right)$ in $B\left(\mathscr{H}_{n}, \mathscr{H}_{n}\right)$ and a matrix $X$ as in (a) such that $A=U X, X=U^{*} A$.

(c) If $A \geqq 0$ then $U$ may be chosen to be an isometry in (b).

Proof. (a) Let $V_{i}$ be the isometry from $\mathscr{H}$ into $\mathscr{H}_{n}$ given by $V_{i} h=(0,0, \cdots, 0, h, 0, \cdots)$ where the vector $h$ appears as the $i$ th coordinate. If $h, k$ belong to $\mathscr{H}$ then $\left(K_{i j} h, k\right)=\left(K V_{j} h, V_{i} k\right)=$ $\left(\sqrt{K} V_{j} h, \sqrt{K} V_{i} k\right)$. Hence $K_{i j}=\left(\sqrt{K} V_{i}\right)^{*}\left(\sqrt{K} V_{j}\right)$. Let $\Phi$ be an isometry 
from $\mathscr{H}$ onto $\mathscr{H}_{n}$. Then $X_{i}=\Phi^{*} \sqrt{K} V_{i} \in B(\mathscr{H}, \mathscr{H})$ and $X_{i}^{*} X_{j}=K_{i j}$. (b), (c) Choose $X$ as in (a) so that $A^{*} A=X^{*} X$. Then

$$
V \sqrt{A^{*} A} f=X f
$$

defines an isometry $V$ from $\mathscr{R}\left(\sqrt{A^{*} A}\right)^{-}$onto $\mathscr{R}(X)^{-}$. Since $\mathscr{R}(X)^{\perp}=$ $\Phi^{*}\left(\mathscr{N}\left(\sqrt{\left.A^{*} A\right)}\right) \oplus \mathscr{H} \oplus \mathscr{H} \oplus \cdots \oplus \mathscr{H}\right.$ it is clear $V$ can be extended to an isometry on $\mathscr{H}_{n}$. This proves (c) and to complete the proof of (b) use the polar factorization $A=W V \overline{A^{*} A}$ and put $U=W V^{*}$.

REMARK. Lemma $3^{\prime}$ is also valid for infinite matrices $K$ (or $A$ ) that define bounded operators on the direct sum of countably many copies of $\mathscr{H}$.

Proof of Theorem 1. Define the Hilbert space $\mathscr{K}=\mathscr{H}_{1} \oplus$ $\mathscr{H}_{2} \oplus \cdots$ where $\mathscr{H}_{i}=\mathscr{H}, i=1,2, \cdots$, with the natural inner product. Let $V_{i}(i \geqq 1)$ be the isometry from $\mathscr{H}$ into $\mathscr{K}$ given by $V_{i} h=$ $\left(h_{1}, h_{2}, \cdots\right)$ where $h_{i}=h$ and $h_{j}=0$ for $j \neq i$. Let $\mathscr{R}=\left\{t_{i}: i=\right.$ $1,2, \cdots\}$ be a dense set of points in $\mathscr{G}$. Define the non negativedefinite, bounded operator-valued matrices

$$
K^{(n)}=K\left(t_{i}, t_{j}\right), \quad i, j=1, \cdots, n .
$$

By Lemma 3 there is an upper triangular operator-valued matrix $T^{(n)}$ for which $T^{(n) *} T^{(n)}=K^{(n)}$ and moreover from the construction, if $m \leqq n$ then $K^{(m)}=K_{m}^{(n)}=\left(T_{m}^{(n)}\right)^{*}\left(T_{m}^{(n)}\right)$. Let $T$ be the formal infinite upper triangular matrix whose $n^{\text {th }}$ column is the $n^{\text {th }}$ column of $T^{(n)}$, $n=1,2, \cdots$. For each $t_{l} \in \mathscr{R}$ define

$$
\widetilde{X}\left(t_{l}\right)=\sum_{i=1}^{l} V_{i} T_{i l} \text {. }
$$

Then, if $m=\min (k, l)$,

$$
\begin{aligned}
\widetilde{X}\left(t_{k}\right)^{*} \widetilde{X}\left(t_{l}\right) & =\left(\sum_{j=1}^{k} V_{j} T_{j k}\right)^{*}\left(\sum_{i=1}^{l} V_{i} T_{i l}\right) \\
& =\sum_{j=1}^{k} \sum_{i=1}^{l} T_{j k}^{*} V_{j}^{*} V_{i} T_{i l} \\
& =\sum_{i=1}^{m} T_{i k}^{*} T_{i l}=K\left(t_{k}, t_{l}\right) .
\end{aligned}
$$

From this it follows that

$$
|\tilde{X}(t)-\tilde{X}(s)| \leqq|K(t, t)-K(s, t)|+|K(s, s)-K(t, s)|,
$$

for any $t, s$ in $\mathscr{R}$. Using the completeness of $B(\mathscr{H}, \mathscr{K})$ and the continuity of $K$ we can therefore extend $\tilde{X}$ to a function $X$ from $\mathscr{G}$ into $B(\mathscr{H}, \mathscr{K})$ that satisfies the same inequalities for all $t, s$ in 
G. The function $X$ is then continuous and $X(t)^{*} X(s)=K(t, s)$.

In the following theorem the condition of separability is removed from $\mathscr{G}$. However, $\mathscr{K}$ will be a nonseparable Hilbert space. The construction below seems to have originated with Naimark [5].

TheOREM 2. Let $\mathscr{G}$ be a Hausdorff space, and let $K(\cdot, \cdot)$ be as in Theorem 1. Then there is a Hilbert space $\mathscr{K}$ and a continuous function $X(t)$ from $\mathscr{G}$ into $B(\mathscr{H}, \mathscr{K})$ such that $X^{*}(t) X(s)=K(t, s)$.

Proof. Let $\mathscr{L}$ be the vector space of functions $\xi: \mathscr{G} \rightarrow \mathscr{H}$ that vanish at all but a finite number of points of $\mathscr{G}$, and for $\xi, \eta$ in $\mathscr{L}$ put

$$
(\xi, \eta)=\sum_{s, t}(K(s, t) \xi(t), \eta(s))
$$

Let $\mathscr{N}=\{\xi \in \mathscr{L}:(\xi, \xi)=0\}$. Then $\mathscr{N}$ is a subspace of $\mathscr{L}$ and

$$
(\xi+\mathscr{N}, \xi+\mathscr{N})=(\xi, \eta)
$$

defines an inner product on $\mathscr{K}_{0}=\mathscr{L} / \mathscr{N}$. Let $\mathscr{K}$ be the completion of $\mathscr{K}_{0}$. For $s \in \mathscr{G}$ and $h \in \mathscr{H}$ define

$$
\xi_{s} h(t)=\left\{\begin{array}{lll}
h & \text { if } t=s \\
0 & \text { if } & t \neq s
\end{array} .\right.
$$

Then $X(s) h=\xi_{s} h+\mathscr{N}$ defines a bounded operator $X(s)$ from $\mathscr{H}$ into $\mathscr{K}$. A simple computation shows that $X(t)^{*} X(s)=K(t, s)$. This implies $|X(t)-X(s)|^{2} \leqq|K(t, t)-K(t, s)|+|K(s, s)-K(s, t)|$, so the continuity of the map $s \rightarrow X(s)$ follows from that of $K$.

\section{REFERENCES}

1. G. D. Allen, An extension of Kolmogorov's theorem for continuous covariances, Proc. Amer. Math. Soc., 39 (1973), 214-216.

2. R. G. Douglas, On majorization, factorization, and range inclusion of operators on Hilbert space, Proc. Amer. Math. Soc., 17 (1966), 413-415.

3. D. K. Faddeev and V. N. Fadeeva, Computational Methods in Linear Algebra, Figmatgiz, Moscow, 1960; English transl., Freeman, San Francisco, Calif., 1963.

4. P. A. Fillmore and J. P. Williams, On operator ranges, Advances in Mathematics, 7 (1971), 254-281.

5. M. A. Naimark, On a representation of additive operator set functions, Comptes Rendus (Doklady) Acad. Sci. USSR, 41 (1943), 359-361.

Received March 25, 1975 and in revised form November 4, 1975.

TEXAS A \& M UNIVERSITY

AND

INDIANA UNIVERSITY 


\section{PACIFIC JOURNAL OF MATHEMATICS}

\section{EDITORS}

RICHARD ARENS (Managing Editor)

University of California

Los Angeles, California 90024

\author{
R. A. Beaumont \\ University of Washington \\ Seattle, Washington 98105
}

\section{J. DugundjI}

Department of Mathematics University of Southern California Los Angeles, California 90007

D. Gilbarg and J. Milgram

Stanford University

Stanford, California 94305

\section{ASSOCIATE EDITORS}
E. F. BECKENBACH
B. H. NeumanN
F. WOLF
K. YoshidA

\section{SUPPORTING INSTITUTIONS}

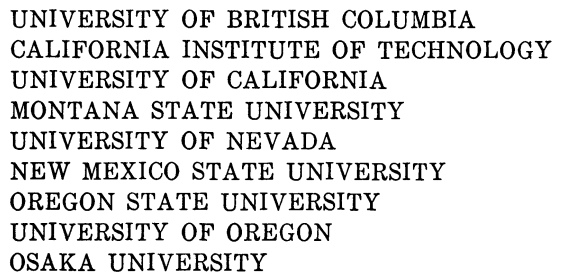

UNIVERSITY OF BRITISH COLUMBIA CALIFORNIA INSTITUTE OF TECHNOLOGY UNIVERSITY OF CALIFORNIA MONTANA STATE UNIVERSITY UNIVERSITY OF NEVADA NEW MEXICO STATE UNIVERSITY OSAKA UNIVERSITY OREGON STATE UNIVERSITY UNIVERSITY OF OREGON

\author{
UNIVERSITY OF SOUTHERN CALIFORNIA \\ STANFORD UNIVERSITY \\ UNIVERSITY OF TOKYO \\ UNIVERSITY OF UTAH \\ WASHINGTON STATE UNIVERSITY \\ UNIVERSITY OF WASHINGTON \\ AMERICAN MATHEMATICAL SOCIETY
}

The Supporting Institutions listed above contribute to the cost of publication of this Journal, but they are not owners or publishers and have no responsibility for its content or policies.

Mathematical papers intended for publication in the Pacific Journal of Mathematics should be in typed form or offset-reproduced, (not dittoed), double spaced with large margins. Please do not use built up fractions in the text of your manuscript. You may however, use them in the displayed equations. Underline Greek letters in red, German in green, and script in blue. The first paragraph or two must be capable of being used separately as a synopsis of the entire paper. Items of the bibliography should not be cited there unless absolutely necessary, in which case they must be identified by author and Journal, rather than by item number. Manuscripts, in triplicate, may be sent to any one of the editors. Please classify according to the scheme of Math. Reviews, Index to Vol. 39. All other communications should be addressed to the managing editor, or Elaine Barth, University of California, Los Angeles, California, 90024.

The Pacific Journal of Mathematics expects the author's institution to pay page charges, and reserves the right to delay publication for nonpayment of charges in case of financial emergency.

100 reprints are provided free for each article, only if page charges have been substantially paid. Additional copies may be obtained at cost in multiples of 50 .

The Pacific Journal of Mathematics is issued monthly as of January 1966. Regular subscription rate: $\$ 72.00$ a year $(6$ Vols., 12 issues). Special rate: $\$ 36.00$ a year to individual members of supporting institutions.

Subscriptions, orders for back numbers, and changes of address should be sent to Pacific Journal of Mathematics, 103 Highland Boulevard, Berkeley, California, 94708.

PUBLISHED BY PACIFIC JOURNAL OF MATHEMATICS, A NON-PROFIT CORPORATION

Printed at Kokusai Bunken Insatsusha (International Academic Printing Co., Ltd.), 8-8, 3-chome, Takadanobaba, Shinjuku-ku, Tokyo 160, Japan. 


\section{Pacific Journal of Mathematics}

\section{Vol. 61, No. 2 December, 1975}

Graham Donald Allen, Francis Joseph Narcowich and James Patrick Williams, An operator version of a theorem of Kolmogorov .......................

Joel Hilary Anderson and Ciprian Foias, Properties which normal operators share with normal derivations and related operators . . . . . . . . . . . . . . . . . . . . .

Constantin Gelu Apostol and Norberto Salinas, Nilpotent approximations and

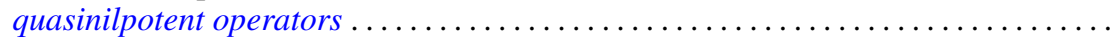

James M. Briggs, Jr., Finitely generated ideals in regular $F$-algebras . . . . . . . . . . .

Frank Benjamin Cannonito and Ronald Wallace Gatterdam, The word problem and power problem in 1-relator groups are primitive recursive ..................

Clifton Earle Corzatt, Permutation polynomials over the rational numbers ...........

L. S. Dube, An inversion of the $S_{2}$ transform for generalized functions . . . . . . . . . . William Richard Emerson, Averaging strongly subadditive set functions in unimodular

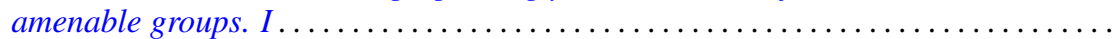

Barry J. Gardner, Semi-simple radical classes of algebras and attainability of

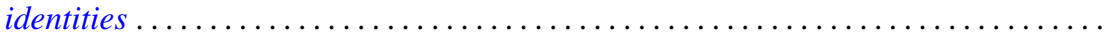

Irving Leonard Glicksberg, Removable discontinuities of A-holomorphic functions ....

Fred Halpern, Transfer theorems for topological structures . . . . . . . . . . . . . . .

H. B. Hamilton, T. E. Nordahl and Takayuki Tamura, Commutative cancellative

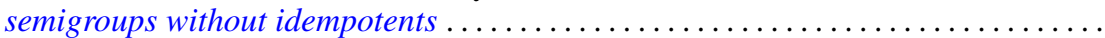

Melvin Hochster, An obstruction to lifting cyclic modules .....................

Alistair H. Lachlan, Theories with a finite number of models in an uncountable power

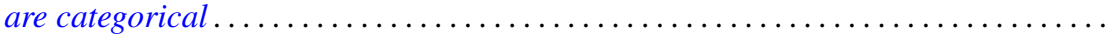

Kjeld Laursen, Continuity of linear maps from $C^{*}$-algebras . . . . . . . . . . . . .

Tsai Sheng Liu, Oscillation of even order differential equations with deviating arguments ....

Jorge Martinez, Doubling chains, singular elements and hyper- $Z$

Mehdi Radjabalipour and Heydar Radjavi, On the geometry of num Thomas I. Seidman, The solution of singular equations, I. Linear equations in Hilbert

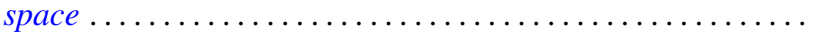

R. James Tomkins, Properties of martingale-like sequences ......

Alfons Van Daele, A Radon Nikodým theorem for weights on von Neumann

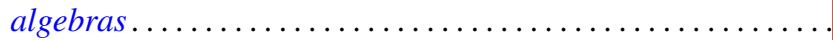

Kenneth S. Williams, On Euler's criterion for quintic nonresidues

Scott Andrew Wolpert, Noncompleteness of the Weil-Petersson metric for Teichmüller

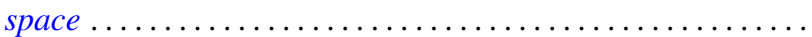

Volker Wrobel, Some generalizations of Schauder's theorem in locally convex

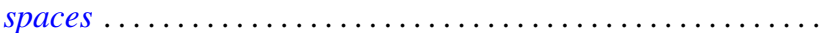

Kelly Denis McKennon, Corrections to: "Multipliers of type $(p, p)$ "; "Multipliers of type $(p, p)$ and multipliers of the group $L_{p}$-algebras"; "Multipliers and the

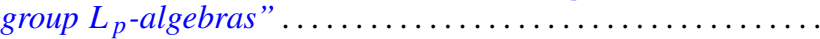

Andrew M. W. Glass, W. Charles (Wilbur) Holland Jr. and Stephen H. McCleary, Correction to: " $a *$-closures to completely distributive lattice-ordered

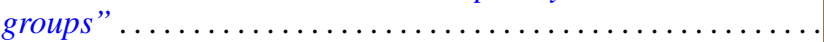

Zvi Arad and George Isaac Glauberman, Correction to: "A characteristic subgroup of

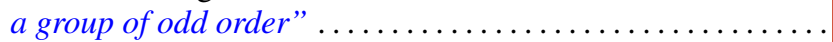

Roger W. Barnard and John Lawson Lewis, Correction to: "Subordination theorems

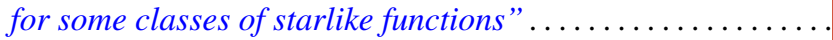

